\title{
The Fatty Acid Content of the Bordetella pertussis Endotoxin
}

\author{
By ANGELIKA STARKLOFF† AND LADISLAS SZABÓ* \\ Equipe de Recherche No 55 du Centre National de la Recherche Scientifique, Institut de \\ Biochimie, Université de Paris-Sud, 91405 Orsay, France
}

(Received 9 April 1985; revised 22 July 1985)

The fatty acid content of Bordetella pertussis endotoxin has been estimated by several methods. Expressed as 3-hydroxytetradecanoic acid, it was $0.74 \mu \mathrm{mol}$ (mg lyophilized material) ${ }^{-1}$, $0.38 \mu \mathrm{mol}$ being ester-bound, and $0.32 \mu \mathrm{mol}$ in amide linkage. Reported molar ratios of esterbound to amide-bound fatty acids in endotoxins of various bacterial species range from 2.4 to 2 in $B$. pertussis, to 5 to 2 in Salmonella minnesota; according to these figures large differences must exist in the degree of substitution, and the substitution pattern of the glucosaminyl- $\beta-1,6-$ glucosamine unit present in the hydrophobic region of endotoxins. When fatty acids, released by acid and alkaline hydrolyses of the $B$. pertussis endotoxin, were extracted into chloroform, unidentified chromogenic substances appearing in the extract interfered with their colorimetric estimation; no interference was observed when hexane was used instead of chloroform.

\section{INTRODUCTION}

Endotoxins of Gram-negative bacteria are lipopolysaccharides built up from a hydrophilic polysaccharide chain, and a hydrophobic region. The latter contains, as major constituent, phosphorylated glucosaminyl- $\beta$-1,6-glucosamine, to which various fatty acids are bound by ester and amide linkages (Hase \& Rietschel, 1976). The extract structure of the hydrophobic region is not known: when cleaved off by mild acid treatment, it appears as a heterogeneous mixture, insoluble in water, usually referred to as 'lipid A'. Structures derived from the glucosaminyl- $\beta$ 1,6-glucosamine disaccharide identified (Imoto et al., 1983; Qureshi et al., 1982; Rosner et al., 1979; Strain et al., 1983; Takayama et al., 1983) in 'lipid A' preparations, when produced by chemical synthesis (Charon et al., 1983; Kiso et al., 1981; Kusumoto et al., 1983; Imoto et al., 1984), so far have failed to reproduce the complete set of biological properties of 'lipid A' preparations (Galanos et al., 1984; Kotani et al., 1983; Lüderitz et al., 1983; Matsuura et al., 1983; Yasuda et al., 1982, 1984). It has been suggested that the nature and type of linkage of the fatty acids attached to the phosphorylated glucosamine disaccharide might be critical for the elicitation of the biological properties of the 'lipid A' preparations.

In view of the foregoing, and of our current interest in the chemical structure (Le Dur et al., 1980) and immunological activities (Ayme et al., 1980; Haeffner-Cavaillon et al., 1982, 1983, 1984) of the Bordetella pertussis endotoxin, a quantitative study was undertaken of the fatty acids present in this endotoxin, and the conditions of their release; the results are reported in this paper.

\section{METHODS}

Cell growth. Culture conditions of Bordetella pertussis cells in the liquid medium of Cohen \& Wheeler (1946), extraction of the endotoxin by the phenol-water procedure (Westphal et al., 1952), and its purification by sedimentation have been described previously (Ayme et al., 1980).

Fatty acid extraction. Alkaline hydroxylamine at $65^{\circ} \mathrm{C}$ (Snyder \& Stephens, 1959), 0.05 M-NaOMe (sodium methoxide) in methanol, and methanol saturated with ammonia gas, both at room temperature, were used to

† Present address: Forschungsinstitut Borstel, Parkallee 1-40, 2061 Borstel, German Federal Republic. 
release ester-bound fatty acids. For estimation of both ester- and amide-bound fatty acids ('total fatty acids'), the endotoxin was treated with $4 \mathrm{M}-\mathrm{HCl}$ at $100^{\circ} \mathrm{C}$ for $2 \mathrm{~h}$ (Haeffner et al., 1977).

\section{RESULTS}

\section{Estimation of total fatty acids}

By colorimetry. Samples (1-2 mg) of B. pertussis endotoxin, dispersed in $0.5 \mathrm{ml} 4 \mathrm{M}-\mathrm{HCl}$, were kept at $100{ }^{\circ} \mathrm{C}$ for $2 \mathrm{~h}$ in sealed tubes. The mixture was brought to dryness by evaporation under vacuum, and dry toluene was evaporated $(3-4$ times, $1 \mathrm{ml}$ ) from the residue to remove any residual mineral acid. Then $2 \mathrm{M}-\mathrm{NaOH}(0.5 \mathrm{ml})$ was added to the dry residue; the tube was sealed, and the mixture was kept at $100{ }^{\circ} \mathrm{C}$ for $2 \mathrm{~h}$. The cooled mixture was acidified $(4 \mathrm{M}-\mathrm{HCl})$ and the fatty acids were extracted with hexane $(3 \times 1.5 \mathrm{ml})$. Ethereal diazomethane solution was added; a few minutes later solvents were removed, and the fatty acids were estimated according to the procedure of Snyder \& Stephens (1959). The results, expressed as $\mu \mathrm{mol} 3-$ hydroxytetradecanoic acid (mg lyophilized endotoxin) $)^{-1}$ (3-hydroxytetradecanoic acid being the most abundant fatty acid present in the endotoxin), gave a value of $0.74(\operatorname{SD} 0.06 ; n=9)$. The same value was obtained if the cooled acid hydrolysate was directly extracted with hexane, and the fatty acids estimated after esterification with diazomethane.

Two samples, when similarly treated except that the fatty acids were extracted with chloroform instead of hexane, gave 1.15 and $1.2 \mu \mathrm{mol}$ 3-hydroxytetradecanoic acid (mg endotoxin $)^{-1}$. Absorption spectra of the coloured solutions obtained with standard methyl 3hydroxytetradecanoate, with fatty acids of the endotoxin extracted with hexane, and with fatty acids of the endotoxin extracted with chloroform, are reproduced in Fig. 1.

By gas-liquid chromatography $(G L C)$. Methyl stearate $(33.84 \mu \mathrm{g})$ was added to a sample $(0.865 \mathrm{mg})$ of endotoxin, and the mixture was sequentially treated with $4 \mathrm{M}-\mathrm{HCl}$ and $2 \mathrm{M}-\mathrm{NaOH}$ as described above. The cooled, acidified mixture was first extracted with hexane $(3 \times 1.5 \mathrm{ml})$ and then with chloroform $(1 \times 1.5 \mathrm{ml})$ : the extracts were then treated separately with ethereal diazomethane solution. The methyl esters remaining after removal of the solvents were dissolved in a known volume $(30 \mu \mathrm{l})$ of ethyl acetate, and $1 \mu \mathrm{l}$ sampes were injected for analysis by GLC [stainless steel column, $2 \mathrm{~m} \times 3.2 \mathrm{~mm}, 3 \%$ SE30 on Gaschrom Q, 100-120 mesh, $100{ }^{\circ} \mathrm{C}-200{ }^{\circ} \mathrm{C}\left(8^{\circ} \mathrm{C} \mathrm{m^{-1 }}\right)$; or stainless steel column, $2 \mathrm{~m} \times 3.2 \mathrm{~mm}, 3 \% 0 \mathrm{~V}-1$ on Gaschrom $\mathrm{Q}, 100-120$ mesh, $120^{\circ} \mathrm{C}-260^{\circ} \mathrm{C}\left(4^{\circ} \mathrm{C} \mathrm{min}-1\right)$; carrier gas: He]. Individual peaks were integrated. The amount of 'total fatty acids' (expressed as above) present in the hexane extract was $0.64 \mu \mathrm{mol}$ (mg endotoxin) $)^{-1}$. No fatty acids were found in the chloroform extract.

Sequential release of ester- and amide-bound fatty acids, and colorimetric estimation

Samples (2-4 mg) of $B$. pertussis endotoxin were treated with the alkaline ( $\mathrm{pH} \mathrm{13-14)}$ hydroxylamine reagent of Snyder \& Stephens (1959) at $65^{\circ} \mathrm{C}$ for $5 \mathrm{~min}$. The cooled mixture was centrifuged, the supernatant removed, and the sediment washed with ethanol $(3 \times 1.5 \mathrm{ml})$. The supernatants and washings were pooled, the solvent evaporated, and the resulting dry residue treated with $4 \mathrm{M}-\mathrm{HCl}\left(0.5 \mathrm{ml}, 100^{\circ} \mathrm{C}, 1 \mathrm{~h}\right)$. The cooled mixture was extracted with hexane, ethereal diazomethane solution was added to the extract, and the fatty acids were estimated according to Snyder \& Stephens (1959). The mean value of eight determinations was $0.38 \mu \mathrm{mol}$ (SD 0.04) ester-bound fatty acid (mg endotoxin) ${ }^{-1}$, calculated as 3-hydroxytetradecanoic acid.

The ethanol-washed sediment was dried in vacuo, and treated with $4 \mathrm{M}-\mathrm{HCl}\left(0.5 \mathrm{ml}, 100{ }^{\circ} \mathrm{C}\right.$, $2 \mathrm{~h})$. Fatty acids were extracted from the coloured mixture with hexane $(3 \times 1.5 \mathrm{ml})$, ethereal diazomethane solution was added to the extract and, after removal of the solvents, fatty acids were estimated colorimetrically. The mean value of eight determinations was $0 \cdot 32$ (SD 0.043 ) $\mu \mathrm{mol}$ amide-bound fatty acid (mg endotoxin $)^{-1}$, calculated as 3-hydroxytetradecanoic acid. From these data the calculated fatty acid content of the B. pertussis endotoxin was $0 \cdot 71$ (SD 0.064) $\mu \mathrm{mol}$ fatty acid (mg endotoxin) $)^{-1}$.

\section{Release of ester-bound fatty acids by treatment with ammonia in methanol}

A sample (11 mg) of the $B$. pertussis endotoxin, placed in a tube, was dispersed (ultrasonic bath, $\left.20^{\circ} \mathrm{C}, 5 \mathrm{~min}\right)$ in anhydrous methanol $(5 \mathrm{ml})$; the mixture was cooled to $0{ }^{\circ} \mathrm{C}$, and saturated 


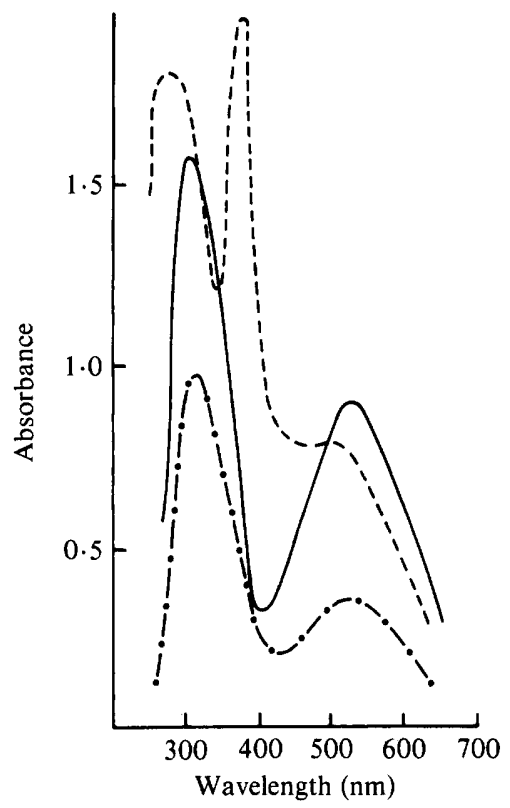

Fig. 1. Absorption spectra of the $\mathrm{Fe}^{3+}$-complexes of fatty hydroxamates formed from methyl 3hydroxytetradecanoate (-) (reference), and from the fatty acid mixture of the B. pertussis endotoxin released by consecutive acid and alkaline hydrolyses, esterified, and extracted with hexane (- $-(-)$; the same extracted with chloroform (----).

with ammonia gas. The tube was sealed with a teflon-lined cap, and kept for $24 \mathrm{~h}$ at room temperature under constant stirring. Ammonia was removed from the mixture by bubbling nitrogen through it, the solvent was evaporated, hexane $(1 \mathrm{ml})$ was added to the residue, the contents were thoroughly mixed (vortex), and then centrifuged. The supernatant was collected and the extraction repeated three times. The pooled extracts were brought to dryness, and treated with $4 \mathrm{M}-\mathrm{HCl}\left(0.5 \mathrm{ml}, 100^{\circ} \mathrm{C}, 2 \mathrm{~h}\right)$. The cooled mixture was extracted with hexane $(3 \times 1.5 \mathrm{ml})$, the solvent evaporated, and the free fatty acids converted into their methyl esters (diazomethane) which were estimated colorimetrically. The residue was suspended in methanol, saturated with ammonia as above, and the procedure was repeated daily until the amount of fatty acid released became negligible $(7 \mathrm{~d})$. The total amount of ester-bound fatty acids was $0 \cdot 31 \mu \mathrm{mol}$ (mg endotoxin) ${ }^{-1}$. The amount of amide-bound fatty acids recovered after acid hydrolysis of the sediment was $0 \cdot 38 \mu \mathrm{mol}$ (mg endotoxin $)^{-1}$.

\section{Release of ester-bound fatty acids with 0.05 M-sodium methoxide in methanol}

$\mathrm{NaOMe}(0.05 \mathrm{M})$ in methanol $(5 \mathrm{ml})$ was added to a sample $(11 \mathrm{mg})$ of $B$. pertussis endotoxin, and the stirred mixture kept in a sealed vessel for $24 \mathrm{~h}$. The mixture was neutralized with acetic acid ( $\mathrm{pH}$ paper), and the solvent was evaporated. The dry residue was extracted with hexane $(3 \times 2 \mathrm{ml})$, and the insoluble material sedimented by centrifugation. Pooled extracts were concentrated, treated with a few drops of ethereal diazomethane to ensure that all the fatty acids were present as methyl esters, and the fatty acids estimated colorimetrically. The sediment was treated with $0.05 \mathrm{M}-\mathrm{NaOMe}$ as above, and the procedure was repeated until the amount of fatty acids recovered was negligible $(7 \mathrm{~d})$. The amount of amide-bound fatty acids remaining in the residue was then determined colorimetrically after acid hydrolysis $\left(4 \mathrm{M}-\mathrm{HCl}, 100^{\circ} \mathrm{C}, 2 \mathrm{~h}\right)$, extraction with hexane $(3 \times 2 \mathrm{ml})$ and esterification with diazomethane. The amount of esterbound fatty acid was $0.35 \mu \mathrm{mol}$ (mg endotoxin) $)^{-1}$, that of amide-bound fatty acid was $0.39 \mu \mathrm{mol}$ (mg endotoxin) ${ }^{-1}$, both expressed as 3-hydroxytetradecanoic acid. 


\section{DISCUSSION}

Both acid and alkaline hydrolyses have been used to release fatty acids from endotoxins, but no generally applied method appears to be accepted, nor have comparative studies been made. Methods used for the estimation of 'total fatty acids' include hydrolysis with $4 \mathrm{M}-\mathrm{NaOH}$ or $4 \mathrm{M}$ $\mathrm{HCl}$ at $100^{\circ} \mathrm{C}$ for $5 \mathrm{~h}$ (Rietschel et al., 1972), $2 \mathrm{M}-\mathrm{HCl}$ in anhydrous methanol at $85^{\circ} \mathrm{C}$ for $16 \mathrm{~h}$ (Bryn \& Rietschel, 1978), a mixture of $12 \mathrm{ml}$ conc. $\mathrm{HCl}$ (aqueous) and $150 \mathrm{ml} \mathrm{MeOH}$ at $85^{\circ} \mathrm{C}$ for $18 \mathrm{~h}$ (Wollenweber et al., 1983). In the present study 'total fatty acids' were estimated after acid hydrolysis with $4 \mathrm{M}-\mathrm{HCl}\left(100^{\circ} \mathrm{C}, 2 \mathrm{~h}\right)$, followed by treatment with $2 \mathrm{M}-\mathrm{NaOH}\left(100^{\circ} \mathrm{C}, 2 \mathrm{~h}\right)$, as it has been established previously (Haeffner et al., 1977) that with $B$. pertussis endotoxin this procedure gives the highest recovery of fatty acids. If the fatty acids were estimated colorimetrically, the alkaline treatment (required to cleave acyloxy derivatives of hydroxy-fatty acids) could be omitted.

For the estimation of ester-bound fatty acids, transesterification with $0.25 \mathrm{M}-\mathrm{NaOMe}$ at $37{ }^{\circ} \mathrm{C}$ for $15 \mathrm{~h}$ (Broady et al., 1981) or brief (2-3 min) hydroxylaminolysis (Rietschel et al., 1972) have been applied. In the present case the latter method was used, but the time of hydroxylaminolysis at $65^{\circ} \mathrm{C}$ was extended to $5 \mathrm{~min}$. Lengthening the treatment with hydroxylamine was necessary to achieve complete removal of ester-bound fatty acids. The original method was elaborated for the estimation of fatty acids in triglycerides and lecithin, and these substances are more soluble, or at least more easily dispersed in the medium than the very insoluble endotoxin. Further extension of the reaction-time is, however, not advisable, as in the strongly alkaline medium (pH 13-14) incipient release of amide-bound fatty acids also occurs.

For quantitative estimation both the colorimetric method of Snyder \& Stephens (1959), and integration of peaks observed upon GLC of fatty acid methyl esters were used; as the latter gave somewhat lower values, the colorimetric method was used preferentially. When chloroform was used to extract the fatty acids released from the endotoxin by successive acid and alkaline hydrolyses, much higher values were measured by the colorimetric method than in those instances when hexane was used. That this was not due to incomplete extraction could be established by extracting the aqueous solution first with hexane, and then with chloroform: no fatty acids could be detected by GLC in such chloroform extracts. Furthermore, the internal standard (octadecanoic acid) was quantitatively recovered in the hexane extract. Examination of the spectra of the coloured complex formed upon addition of ferric chloride to solutions of the fatty acid hydroxamates revealed that while samples extracted with hexane gave rise to spectra identical to that obtained with pure, authentic fatty acids, samples extracted with chloroform gave spectra unsuitable for quantitative estimations (Fig. 1).

The total fatty acid content of the B. pertussis endotoxin, calculated as 3-hydroxytetradecanoic acid, was $0.74 \mu \mathrm{mol}$ (mg lyophilized endotoxin) $)^{-1}$, comparable to the figure of $0.75 \mu \mathrm{mol}$ (mg endotoxin) ${ }^{-1}$ published for Chromobacterium violaceum NCTC 9694 (Hase \& Rietschel, 1977), of $1 \cdot 1 \mu \mathrm{mol}$ (mg endotoxin) $)^{-1}$ for Vibrio cholerae (Broady et al., 1981), but much lower than the $2.45 \mu \mathrm{mol}$ (mg endotoxin) ${ }^{-1}$ measured for Salmonella minnesota R595 endotoxin (Wollenweber et al., 1983), which is only composed of two KDO (2-keto-3-deoxyoctonic acid) units and the hydrophobic region. It is somewhat higher than the value of $0.54 \mu \mathrm{mol}$ fatty acids (mg endotoxin) ${ }^{-1}$ found in Bacteroides fragilis NCTC 9342 (Wollenweber et al., 1980).

According to the data obtained by hydroxylaminolysis for ester-bound fatty acids $[0 \cdot 38 \mu \mathrm{mol}$ ( $\mathrm{mg}$ endotoxin $\left.)^{-1}\right]$, and by acid hydrolysis of the de-esterified insoluble residue for the amidebound fatty acids $\left.[0 \cdot 32 \mu \mathrm{mol} \text { (mg endotoxin) })^{-1}\right]$, in $B$. pertussis endotoxin 2.4 ester-bound fatty acids appear to be present for every 2 amide-bound fatty acids. Almost identical figures were obtained when ester-bound fatty acids were released by treatment with ammonia in methanol $\left[0.31 \mu \mathrm{mol}(\mathrm{mg} \text { endotoxin) })^{-1}\right]$, or with $0.05 \mathrm{M}-\mathrm{NaOMe}$ in methanol $[0.35 \mu \mathrm{mol}$ ( $\mathrm{mg}$ endotoxin $\left.)^{-1}\right]$; in all cases the sum of ester- and amide-bound fatty acids came close to the value found for the total amount of fatty acids $\left[0.74 \mu \mathrm{mol}(\mathrm{mg} \text { endotoxin })^{-1}\right]$.

Reported ratios of ester-to-amide-bound fatty acids are 3:2 for Chromobacterium violaceum NCTC 9694 (Hase \& Rietschel, 1977), 4:2 for Vibrio cholerae (Broady et al., 1981) and 5:2 for Salmonella minnesota R595 (Wollenweber et al., 1982) endotoxins; reported ratios for 'lipid A' preparations are $3: 2$ for Escherichia coli K12, strain D31 m4 (Strain et al., 1983), and 4:2 for E. 
coli 08 K27, strain F515 (Imoto et al., 1983) and for Salmonella typhimurium, strain G30/C21 (Qureshi et al., 1982; Takayama et al., 1983). These data suggest that rather large differences are likely to exist in the fine structures of the hydrophobic regions isolated from various Gramnegative bacteria.

The authors thank the Deutsche Forschungsgemeinschaft for a Fellowship (to A.S.).

\section{REFERENCES}

Ayme, G., Caroff, M., Chaby, R., HaefFnerCavaillon, N., Le Dur, A., Moreau, M., Muset, M., Mynard, M.-C., RoumiantzefF, M., Schulz, D. \& SzABó, L. (1980). Biological activities of fragments derived from Bordetella pertussis endotoxin: isolation of a non-toxic, Schwartzman negative lipid A possessing high adjuvant properties. Infection and Immunity 27, 409-415.

Broady, K. W., Rietschel, E. TH. \& LÜDERITZ, O. (1981). The chemical structure of the lipid A component of lipopolysaccharides from Vibrio cholerae. European Journal of Biochemistry 115, 463-468.

BRYN, K. \& RiETSCHEL, E. TH. (1978). L-2-Hydroxytetradecanoic acid as a constituent of Salmonella lipopolysaccharides (lipid A). European Journal of Biochemistry 86, 311-315.

Charon, D., Diolez, Ch., Mondange, M., Sarfati, S. R., Szabó, P., Szabó, L. \& Trigalo, F. (1983). Synthetic studies on structural elements of the hydrophobic region present in bacterial endotoxins. In Bacterial Lipopolysaccharides (ACS Symposium Series 231), pp. 301-316. Edited by L. Anderson \& F. M. Unger. Washington, DC: American Chemical Society.

Cohen, S. M. \& Wheeler, M. W. (1946). Pertussis vaccine prepared with phase I cultures grown in fluid medium. American Journal of Public Health 36, 371-376.

Galanos, Ch., LehmanN, V., Lüderitz, O., RietSchel, E. Th., Westphal, O., Brade, H., Brade, L., Freudenberg, M., Hansen-HagGe, Th., Lüderitz, Th., McKenzie, G., Schade, U., StrittmatTER, W., TANaMoto, K., Zähringer, U., IMOTO, M., Yoshimura, H., Yamamoto, M., Shimamoto. T., Kusumoto, Sh. \& Shiba, T. (1984). Endotoxic properties of chemically synthesized lipid A part structures. Comparison of synthetic lipid A precursors and synthetic analogues with biosynthetic lipid A precursors and free lipid A. European Journal of Biochemistry 140, 221-227.

HAEFFner, N., Chaby, R. \& SzaBó, L. (1977). Identification of 2-methyl-3-hydroxydecanoic and 2methyl-3-hydroxy-tetradecanoic acids in the "lipid X" fraction of the Bordetella pertussis endotoxin. European Journal of Biochemistry 77, 535-544.

Haeffner-Cavaillon, N., Chaby, R., Cavaillon, J.M. \& SZABó, L. (1982). Lipopolysaccharide receptor on rabbit peritoneal macrophages. I. Binding characteristics. Journal of Immunology 128, 1950-1954.

Haefforer-Cavalllon, N., Cavaillon, J.-M. \& Szabó, L. (1983). Macrophage-dependent polyclonal activation of splenocytes by Bordetella pertussis endotoxin and its isolated polysaccharide and Lipid A regions. Cellular Immunology 74, 1-13.
Haeffner-Cavaillon, N., Cavaillon, J.-M., MoREAU, M. \& SzABó, L. (1984). Interleukine-1 secretion by human monocytes stimulated by the isolated polysaccharide region of the Bordetella pertussis endotoxin. Molecular Immunology 21, 389-395.

HASE, S. \& RiETSChel, E. TH. (1976). Isolation and analysis of the Lipid A backbone. Lipid A structure of lipopolysaccharides from various bacterial groups. European Journal of Biochemistry 63, 101107.

Hase, S. \& Rietschel, E. TH. (1977). The chemical structure of the Lipid A component of lipopolysaccharides from Chromobacterium violaceum NCTC 9694. European Journal of Biochemistry 75, 23-34.

Imoto, M., Kusumoto, S., Shiba, T., NAOKI, H., IWAShita, T., Rietschel, E. Th., WollenWEber, H.-W., Galanos, C. \& Lüderitz, O. (1983). Chemical structure of $E$. coli Lipid A : linkage site of acyl groups in the disaccharide backbone. Tetrahedron Letters 24, 4017-4020.

Imoto, M., Yoshimura, H., Yamamoto, M., Shimamoto, T., Kusumoto, S. \& Shiba, T. (1984). Chemical synthesis of phosphorylated tetraacyl disaccharide corresponding to a biosynthetic precursor of Lipid A. Tetrahedron Letters 25, 2667-2670.

Kiso, M., Nishiguchi, H., Hasegawa, A., OKumura, H. \& Azuma, 1. (1981). Biological activities of fundamental carbohydrate skeleton of lipid A containing amide-linked 3-hydroxytetradecanoic acid. Agricultural and Biological Chemistry 45, 1523 1525.

Kotani, S., Takada, H., Tsujimoto, M., Ogawa, T., Mori, Y., SaKuta, M., KaWaSaki, A., INaGe, M., Kusumoto, S., Shiba, T. \& Kasai, N. (1983). Immunobiological activities of synthetic lipid A analogs and related compounds as compared with those of bacterial lipopolysaccharide, Re-glycolipid, lipid A and muramyl dipeptide. Infection and Immunity 41, 758-773.

Kusumoto, S., Inage, M., ChaKi, H., Imoto, M., Shimamoto, T. \& Shiba, T. (1983). Chemical synthesis of lipid A for the elucidation of structureactivity relationships. In Bacterial Lipopolysaccharides (ACS Symposium Series 231), pp. 237-254. Edited by L. Anderson and F. M. Unger. Washington, DC: American Chemical Society.

Le Dur, A., Chaby, R. \& Szabó, L. (1980). Isolation of two protein-free and chemically different lipopolysaccharides from Bordetella pertussis phenol-extracted endotoxin. Journal of Bacteriology 143, 78-88.

Lüderitz, O., Tanamoto, K.-I., Galanos, Ch., WESTPHAL, O., ZÄHRINGER, U., RIETSCHEL, E. TH., Kusumoto, S. \& SHiba, T. (1983). Structural 
principles of lipopolysaccharides and biological properties of synthetic partial structures. In Bacterial Lipopolysaccharides (ACS Symposium Series 231), pp. 3-17. Edited by L. Anderson and F. M. Unger. Washington, DC: American Chemical Society.

Matsuura, M., Kojima, Y., Нomma, J. Y., KaWA, N., Shibata, M., Kusumoto, S. \& Shiba, T. (1983). Interferon-inducing, pyrogenic and proclotting enzyme of horseshoe crab activation activities of chemically synthesized lipid A analogues. European Journal of Biochemistry 137, 639-642.

Qureshi, N., TAKayama, K. \& Ribi, E. (1982). Purification and structural determination of nontoxic Lipid A obtained from the lipopolysaccharide of Salmonella typhimurium. Journal of Biological Chemistry 257, 11808-11815.

Rietschel, E. Th., Gottert, H., Lüderitz, O. \& WESTPHAL, O. (1972). Nature and linkages of fatty acids present in the lipid-A component of Salmonella lipopolysaccharides. European Journal of Biochemistry 28, 166-173.

RosNer, M. R., TANG, J.-Y., BARZILAY, I. \& KHORANA, H. G. (1979). Structure of the Lipopolysaccharide from an Escherichia coli heptose-less mutant. Journal of Biological Chemistry 254, 5906-5917.

SNYDER, F. \& STEPHENS, N. (1959). A simplified spectrophotometric determination of ester groups in lipids. Biochimica et biophysica acta 34, 244-245.

Strain, S. M., Fesik, S. W. \& Armitage, I. M. (1983). Structure and metal-binding properties of lipopolysaccharides from heptoseless mutants of Escherichia coli studied by ${ }^{13} \mathrm{C}$ and ${ }^{31} \mathrm{P}$ nuclear magnetic resonance. Journal of Biological Chemistry 258, 13466-13477.

Takayama, K., Qureshi, N. \& Mascagni, P. (1983). Complete structure of Lipid A obtained from the lipopolysaccharides of the heptoseless mutant of Salmonella typhimurium. Journal of Biological Chemistry 258, 12801-12803.

WESTPHAL, O., LÜDERITZ, O. \& BISTER, F. (1952). Über die Extraktion von Bakterien mit Phenol/Wasser. Zeitschrift für Naturforschung B7, 148-155.

Wollenweber, H. W., Rietschel, E. Th., Hofstad, T., Weintraub, A. \& Lindberg, A. A. (1980). Nature, type of linkage, quantity, and absolute configuration of (3-hydroxy) fatty acids in lipopolysaccharides from Bacteroides fragilis NCTC 9343 and related strains. Journal of Bacteriology 144, 898903.

WOLlENWEBER, H.-W., BROADY, K. W., LÜDERITZ, O. \& RietsChel, E. TH. (1982). The chemical structure of Lipid A. Demonstration of amide-linked 3acyloxyacyl residues in Salmonella minnesota $\mathrm{Re}$ lipopolysaccharide. European Journal of Biochemistry 124, 191-198.

Wollenweber, H. W., SChlecht, S., LÜDeritz, O. \& RIETSCHEL, E. TH. (1983). Fatty acid in lipopolysaccharides of Salmonella species grown at low temperature. Identification and position. European Journal of Biochemistry 130, 167-171.

Yasuda, T., Kanegasaki, S., Tsumita, T., Tadakuma, T., Homma, J. Y., Inage, M., Kusumoto, S. \& Shiba, T. (1982). Biological activity of chemically synthesized analogues of Lipid A. Demonstration of adjuvant effect in hapten-sensitized liposomal system. European Journal of Biochemistry 124, 405-407.

Yasuda, T., Kanegasaki, S., Tsumita, T., Tadakuma, T., IKEWAKI, N., Homma, J. Y., INAGE, M., Kusumoto, S. \& Shiba, T. (1984). Further study of biological activities of chemically synthesized analogues of lipid A in artificial membrane vesicles. European Journal of Biochemistry 140, 245-248. 